\title{
Burkholderia kirstenboschensis sp. nov. nodulates papilionoid legumes indigenous to South Africa
}

Emma T. Steenkampa, Elritha van Zyla, Chrizelle W. Beukesa, Juanita R. Avontuura, Wai

Yin Chanª, Marike Palmera, Lunghile S. Mthombenia, Francina L. Phalaneb, T. Karabo

Seremea, Stephanus N. Venter ${ }^{a}$

aDepartment of Microbiology and Plant Pathology, Faculty of Natural and Agricultural Sciences, Forestry and Agricultural Biotechnology Institute, University of Pretoria, Pretoria, South Africa

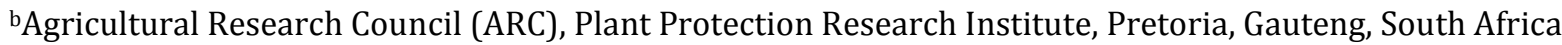

Email addresses:

Emma.steenkamp@up.ac.za

Elritha.vanzyl@fabi.up.ac.za

Chrizelle.beukes@fabi.up.ac.za

Juanita.avontuur@fabi.up.ac.za

Annie.chan@fabi.up.ac.za

Marike.duplessis@fabi.up.ac.za

MthombeniL@dwa.gov.za

PhalaneF@arc.agric.za

Theodorah.Sereme@ZA.nestle.com

Fanus.venter@up.ac.za

Corresponding author: Stephanus N. Venter (프us.venter@up.ac.za)

Tel: +27124204100

Postal address: Department of Microbiology and Plant Pathology, Faculty of Natural and Agricultural Sciences, University of Pretoria, Lunnon Road, Hillcrest, Pretoria, Republic of South Africa, 0002 


\section{Abstract}

Despite the diversity of Burkholderia species known to nodulate legumes in introduced and native regions, relatively few taxa have been formally described. For example, the Cape Floristic Region of South Africa is thought to represent one of the major centres of diversity for the rhizobial members of Burkholderia, yet only five species have been described from legumes occurring in this region and numerous are still awaiting taxonomic treatment. Here, we investigated the taxonomic status of 12 South African root-nodulating Burkholderia isolates from native papilionoid legumes (Hypocalyptus coluteoides, H. oxalidifolius, H. sophoroides and Virgilia oroboides). Analysis of four gene regions (16S $\mathrm{rRNA}, \operatorname{rec} A, a t p D$ and $r p o B$ ) revealed that the isolates represent a genealogically unique and exclusive assemblage within the genus. Its distinctness was supported by all other aspects of the polyphasic approach utilized, including the genome-based criteria DNA-DNA hybridization $(\geq 70.9 \%)$ and average nucleotide identities ( $\geq 96 \%)$. We accordingly propose the name $B$. kirstenboschensis sp. nov. for this taxon with isolate $\mathrm{Kb} 15^{\mathrm{T}}$ (=LMG $28727^{\mathrm{T}}$; =SARC $695^{\mathrm{T}}$ ) as its type strain. Our data showed that intraspecific genome size differences $(\geq 0.81 \mathrm{Mb})$ and the occurrence of large DNA regions that are apparently unique to single individuals $116-23 \%$ of an isolate's genome) can significantly limit the value of data obtained from DNA-DNA hybridization experiments. Substitution of DNA-DNA hybridization with whole genome sequencing as a prerequisite for the description of Burkholderia species will undoubtedly speed up the pace at which their diversity are documented, especially in hyperdiverse regions such as the Cape Floristic Region. 
Keywords: Hypocalyptus; Virgilia; beta-rhizobia; DNA-DNA hybridization; average nucleotide identity (ANI); Burkholderia

All sequences generated in this study were submitted to the European Nucleotide Archive (https://www.ebi.ac.uk) and received the following accession numbers: atpD (LN795810-LN795821); rроB (LN795797-LN795808); atpD for B. aspalathi LMG 27731 ${ }^{\mathrm{T}}$ (LN795809); rpoB for B. rhynchosiae LMG $27174^{\mathrm{T}}$ (LN795788), B. phytofirmans LMG 22487T (LN795789), B. phenazinium LMG 2247T (LN798790), B. sartisoli LMG 24000 ${ }^{\mathrm{T}}$ (LN795791), B. ginsengisoli LMG 24044 ${ }^{\mathrm{T}}$ (LN795792), B. aspalathi LMG 27731

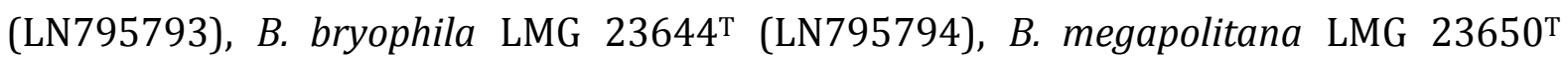
(LN795795) and B. terrae LMG 23368 (LN795796).

\section{Introduction}

Since the initial discovery that Burkholderia tuberum is capable of nodulating several species of the South African legume Cyclopia [25], many additional Burkholderia species have been demonstrated to efficiently establish the nitrogen-fixing symbiosis with a variety of legumes. To date, formal descriptions have been provided for 15 of these rhizobial or root-nodulating Burkholderia species [10, 11, 13, 29, 46, 64, 65, 76, 79]. Among them, only five species (including B. tuberum) have been described as symbionts of South African legumes. The other four species also nodulate legumes in the subfamily Papilionoideae, where both B. sprentiae and B. dilworthii were isolated from Lebeckia ambigua [22, 24], B. rhynchosiae originated from Rhynchosia ferulifolia [23] and B. aspalathi was isolated from the root nodules of Aspalathus abietina [47]. 
In comparison to the knowledge available for rhizobial genera in the Alphaproteobacteria, which have been studied for more than a century [80], our understanding of the diversity, distribution and evolution of the legume symbionts in the genus Burkholderia (class Betaproteobacteria, family Burkholderiaceae [30]) is limited. Research during the last decade has shown that legumes are often associated with a large diversity of Burkholderia symbionts, particularly where the root-nodulating bacteria of indigenous or endemic host species were explored [4, 5, 7, 8, 12, 53]. Phylogenetic analyses of various protein-coding genes have also shown that the association of these legumes with their Burkholderia symbionts likely represents an ancient partnership with a long and complex evolutionary history [5, 7]. For example, the South African Cape Floristic Region (CFR) with its indigenous legumes, some of which trace their origins to the early Oligocene [62], represent a unique centre of diversity for the rhizobial species of this genus [5, 42].

This study investigated the taxonomic status of 12 Burkholderia isolates that were originally isolated from the root nodules of the papilionoid hosts Hypocalyptus coluteoides, H. oxalidifolius, H. sophoroides and Virgilia oroboides growing in various locations in the CFR of South Africa [5]. Based on sequence analyses of the $16 \mathrm{~S}$ ribosomal RNA (rRNA) and recombinase A $(\operatorname{rec} A)$ genes, these isolates were suggested to represent a distinct group nested within the so-called "environmental clade" of Burkholderia [5]. This clade was recently suggested to represent a new genus (i.e., "Caballeronia" as proposed by Gyaneshwar et al. [36] or "Paraburkholderia" as proposed by Sawana et al. [61]; neither proposal have been formally implemented and a type species for this new taxon has not been identified). This proposed generic taxon includes most of the described rhizobia, as well as the plant associated species, but 
excludes all clinically important Burkholderia species. The specific aims of this study were to (i) evaluate the conspecificity of the 12 South African isolates, (ii) evaluate their uniqueness within the overall genus and (iii) to provide a formal description of the taxon thus delineated. To achieve these aims, we utilized a polyphasic approach, where a range of phenotypic characters, phylogenetic information using Multi-Locus Sequence Analysis (MLSA) and genome-based criteria such as DNA-DNA hybridization and average nucleotide identities (ANI) $[33,39,59]$ were used. To accomplish the latter, we also determined the whole genome sequences for two isolates of our newly recognized taxon.

\section{Materials and Methods}

\subsection{Bacterial strains and growth conditions}

The 12 Burkholderia isolates all originated from locations in the Western and Eastern Cape Provinces of South Africa. Three isolates (HC1.1be, HC1.1bc and HC1.1a2) associated with $H$. sophoroides were recovered from soil collected in Old du Toit's Kloof Pass, two isolates (RAU2b and RAU2d2) were recovered from H. coluteoides growing at the Storms River Bridge, and two isolates originated from $H$. oxalidifolius (RAU6.4d and RAU6.4f) occurring in the Fernkloof Nature Reserve. Five isolates (Kb2, Kb13, Kb14, $\mathrm{Kb} 16$ and $\mathrm{Kb}^{\mathrm{T}} \mathrm{T}$ ) were recovered from nodules of $V$. oroboides occurring in the Kirstenbosch National Botanical Gardens. The capacity of these isolates to nodulate their original hosts and/or other hosts such as Vigna unguiculata (cowpea) or Macroptilium atropurpureum (siratro) has been demonstrated previously [5]. Isolate $\mathrm{Kb} 15^{\mathrm{T}}$ is also available from the Belgian Coordinated Collections of Microorganisms (Universiteit Gent, Belgium; LMG 28727T) or from the South African Rhizobium 
Collection (Pretoria, South Africa; SARC 695'T). For comparative purposes, B. caledonica strain LMG $19076^{\mathrm{T}}$, B. fungorum strain LMG 16225' , B. megapolitana strain LMG $23650^{\mathrm{T}}$ and B. dilworthii strain LMG $27173^{\mathrm{T}}$ were also included in the study.

All isolates were routinely grown at $28{ }^{\circ} \mathrm{C}$ on Tryptone Yeast Extract Agar (TYA) enriched with $\mathrm{CaCl}_{2} .2 \mathrm{H}_{2} \mathrm{O}(0.088 \mathrm{~g} / \mathrm{l})$ or on Yeast Mannitol Agar (YMA). Isolates were preserved at $-70{ }^{\circ} \mathrm{C}$ in $20 \%$ glycerol as part of the University of Pretoria's Rhizobium Culture Collection.

\subsection{S rRNA gene analysis and MLSA}

This study utilized the previously determined sequences for the $16 \mathrm{~S}$ rRNA and recA genes [5], together with those for the genes $a t p D$ and $r p o B$ that respectively encode the beta subunits for ATP synthase and RNA polymerase. The atpD and $r p o B$ gene fragments were amplified with primers atpDF (5' GAT CGT ACA GTG CAT CGG 3') and $\operatorname{atpDR}$ (5' ATC GTG CCG ACC ATG TAG 3') [3] and primers RpoB-1394F (5' TGG CGG AAA ACC AGT TCC GCG 3') and RpoB-2430R (5' AGC CGT TCC ACG GCA TGA ACG 3'), respectively. The latter primer set was designed based on publicly available rpoB sequences by making use of BioEdit v7.0.5.3 [37] and Primer3 [60]. These two primer sets targeted, respectively, 1200 base pair (bp) and $1000 \mathrm{bp}$ regions of the atpD and rpoB genes (see Table S1 for details regarding PCR and cycling conditions).

PCR products were cleaned using polyethylene glycol precipitation [69] and sequenced in both directions using the original PCR primers for $r p o B$ and specific sequencing primers for $a t p D$ [3]. For this purpose the ABI PRISM Big Dye Terminator version 3.1 Cycle Sequencing Kit (Applied Biosystems, CA) and an ABI 377 Automated Capillary 
DNA sequencer (Applied Biosystems) were utilized. The $a t p D$ and $r p o B$ sequences were then manually curated using ChromasLite v2.01 (Technelysium, Queensland, Australia) and BioEdit.

For 10 of the Burkholderia isolates examined in this study, single gene nucleotide datasets were compiled for the $a t p D$ and $r p o B$ sequences generated here and the $16 \mathrm{~S}$ rRNA and recA sequences determined previously (see Beukes et al. [5] for accession numbers). For isolates $\mathrm{Kb}_{15} \mathrm{~T}$ and RAU2d2, the relevant gene sequences used in the nucleotide datasets were obtained from the genome sequences of these bacteria (see below). These datasets also included the sequences for the recognized type strains of described Burkholderia species as they appear in the List of Prokaryotic Names with Standing in Nomenclature (LPSN) $[26,54]$ (www.bacterio.net). The $16 \mathrm{~S}$ rRNA dataset was aligned with the online version of MAFFT (Multiple Alignment using Fast Fourier Transformation; http://mafft.cbrc.jp/alignment/server/) using the Q-INS-I strategy that takes secondary structure into account [38]. The nucleotide datasets for the protein coding genes were manually aligned according to the inferred amino acid sequences. A concatenated dataset was generated with SequenceMatrix [74].

The 16S rRNA dataset was analyzed using CLC bio Main Workbench v7.03 (QIAGEN, Århus, Denmark) to determine the percentage sequence similarity among the various taxa included. The four single gene datasets and the concatenated dataset were subjected to maximum parsimony and maximum-likelihood phylogenetic analyses. For the maximum parsimony analyses, MEGA6 [72] was utilized to determine the most parsimonious tree(s) by making use of the heuristic tree search algorithm with 1000 random addition-sequence replicates and Tree Bisection-Reconnection (TBR) branch 
swapping. Branch lengths were calculated by means of the average pathway method [50]. For the maximum-likelihood analyses, PhyML v3.1 [35] or MEGA6 [72] were utilized with the best-fit substitution model parameters as indicated by MEGA5 or jModelTest v0.1.01 $[28,35,56,71]$. The $16 \mathrm{~S}$ rRNA data used the model of Tamura and Nei [70], the $a t p D$ data used the TIM2 "transitional" model [56] while the $r p o B, \operatorname{rec} A$ and concatenated datasets all utilized the General Time Reversible model (GTR) [73]; in all cases these models incorporated gamma (G) correction of among site rate variation and a proportion of invariable sites (I). In these analyses the best of the Nearest-Neighbour Interchange (NNI) and Subtree-Pruning-Regrafting (SPR) search algorithms were used for tree searches, which were initiated using the best of five random starting trees. For both the maximum parsimony and maximum-likelihood analyses, branch support was estimated using non parametric bootstrap analysis [27] based on 1000 pseudoreplicates.

\subsection{Phenotypic characterization}

Growth characteristics were studied on TYA, YMA, Tryptone Soy Agar (TSA; Oxoid, England) and MacConkey Agar without crystal violet (MA; Merck, South Africa). Isolates were incubated aerobically at $28^{\circ} \mathrm{C}$ for 3-4 days, except for the experiments with MA, in which case isolate growth was evaluated at 29 and $37^{\circ} \mathrm{C}$, both after $3-4$ days of incubation [58]. Growth of the isolates at $28{ }^{\circ} \mathrm{C}$ in Tryptone Yeast Broth (Oxoid, England), containing either $0.5 \%(\mathrm{wt} / \mathrm{vol})$ or $1 \%(\mathrm{wt} / \mathrm{vol}) \mathrm{NaCl}$, was also evaluated. Cell morphology, size and motility were determined using Zeiss Stereo and compound microscopes and Auxiovision version 4.8 software. The metabolic profiles for the various isolates were determined using API 20NE and API 20E strips (bioMérieux), as well as the Biolog GN2 MicroPlate system (Biolog). All of these tests were performed 
according to the manufacturers' instructions, where incubation was performed at $28{ }^{\circ} \mathrm{C}$ and results recorded after $48 \mathrm{~h}$. Colonies used for inoculating the various test substrates included in these tests were taken from $24 \mathrm{~h}$ to $48 \mathrm{~h}$ old cultures on TSA at $28^{\circ} \mathrm{C}$.

\subsection{DNA-DNA hybridization}

The DNA-DNA hybridization experiments included nine isolates (HC1.1a2, HC1.1be, RAU2b, RAU2d2, RAU6.4d, RAU6.4f, Kb2, Kb13 and $\mathrm{Kb} 15^{\mathrm{T}}$ ) to span the diversity within the new taxon delineated here. The experiments also included the type strains for the species B. fungorum (LMG 16225T), B. caledonica (LMG 19076' $)$, B. megapolitana (LMG $23650^{\mathrm{T}}$ ), B. rhynchosiae (LMG 27174T) and B. dilworthii (LMG 27173 ) which were selected based on their high 16S rRNA similarity to the nine isolates (Fig 1; File S2). High-molecular-weight DNA was prepared from $48 \mathrm{~h}$ TSA cultures using the method of Pitcher et al. [55] with an additional RNase step as described by Cleenwerck et al. [16]. DNA-DNA hybridizations utilized a modified version (see File S1) of the protocol described by Goris et al. [33].

\subsection{Genome sequencing of isolates $\mathrm{Kb} 15^{\mathrm{T}}$ and RAU2d2}

High quality DNA for isolates $\mathrm{Kb}^{\mathrm{T}} \mathrm{5}^{\mathrm{T}}$ and RAU2d2 was subjected to whole genome shotgun sequencing at the Central Analytical Facilities (CAF) of Stellenbosch University. For this purpose, 300 bp chemistry and the 318-chip Ion Torrent ${ }^{\mathrm{TM}}$ PGM (Thermo Fisher Scientific) platform were used to generate single-ended reads. For isolate RAU2d2, pairended read data with 7000 bp inserts were generated. Following removal of adaptor sequences and filtering out of reads and regions of low quality, using FASTQ Quality Trimmer (version 1.0.0) [6] and an in-house python script, the remaining data were 


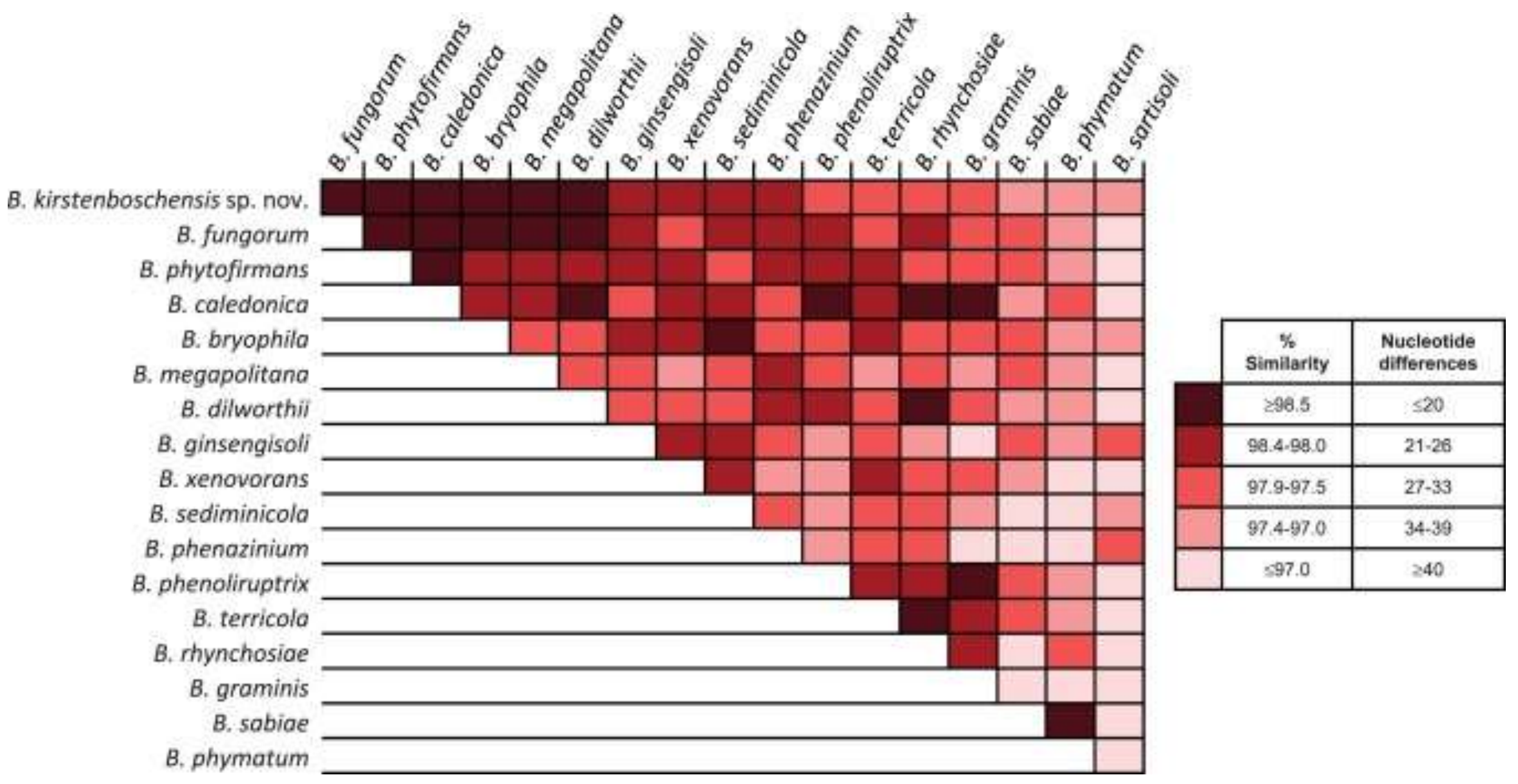

Figure 1. Percentage 16S rRNA gene sequence similarity between B. kirstenboschensis sp. nov. and the type strains of other species of Burkholderia. The analysis utilized the near complete sequence for the 16S rRNA gene where the alignment consisted of 1338 nucleotides and included only those species with $\geq 97 \%$ similarity to one or more of the $B$. kirstenboschensis isolates. The 12 isolates representing $B$. kirstenboschensis share $99.3-100 \%$ with an average of $99.7 \% 16 \mathrm{~S}$ rRNA gene sequence similarity (see File S2 for the similarity matrix). 
assembled. This was done with Newbler version 2.9 [45] using infrastructure at the Bioinformatics and Computational Biology Unit of the University of Pretoria.

The genomic regions shared between isolates $\mathrm{Kb}^{1} 5^{\mathrm{T}}$ and $\mathrm{RAU} 2 \mathrm{~d} 2$ were estimated using Mauve version 2.3.1 [20]. This analysis employed the progressive Mauve function, where a Match Seed weight of $11 \mathrm{bp}$ with the default scoring matrix HOXD [14] was used. From the Mauve progressive backbone output file, the location of each segment that is homologous between the two genomes were extracted, and the sizes of the shared homologous region were summed. Open reading frame (ORF) predictions for the draft genomes were done using the Rapid Annotation using Subsystem Technology (RAST) server $[2,52]$. For comparative purposes, the latter also included the genome sequences for B. dilworthii (LMG 27173 ${ }^{\mathrm{T}}$ ) and B. caledonica (LMG 19076 $)$. Using RAST, ORFs were then annotated using the FIGfams database [2, 49].

\subsection{Average nucleotide identities}

The program, JSpecies [59], was used to calculate ANI-values for the genomes of the sequenced isolates and those of closely related species. Pair-wise comparisons between genomes were made by artificially sectioning genomes into fragments consisting of 1020 nucleotides and then comparing these sections to each other $[33,59]$ using the BLAST algorithm [1]. Only fragments that had more than $30 \%$ identity, as calculated across the entire segment, that aligned over more than $70 \%$ of the length of the fragments were considered homologous and taken into consideration [33]. The percentage identity values obtained for individual fragments were then averaged across all of the fragments to obtain the ANI-values between genomes [33]. 


\section{Results}

\subsection{S rRNA gene analysis and MLSA}

Comparison of the 16S rRNA gene sequences revealed the presence of zero to nine nucleotide differences among the 12 Burkholderia isolates examined in this study (File S2). This corresponded to $16 \mathrm{~S}$ rRNA gene sequence similarities ranging from 99.3 to $100 \%$, where the average similarity among the 12 isolates was $99.7 \%$. Based on the $16 \mathrm{~S}$ rRNA data, these isolates were most similar to B. fungorum (98.9\%), B. phytofirmans (98.8\%), B. caledonica (98.7\%), B. bryophila (98.7\%), B. megapolitana (98.7\%) and B. dilworthii (98.5\%) (Fig. 1, and File S2). However, the 16S rRNA gene sequences for our 12 isolates also shared $\geq 97 \%$ similarity with those of the type strains of B. ginsengisoli, B. xenovorans, B. sediminicola, B. phenazinium, B. phenoliruptrix, B. terricola, B. rhynchosiae, B. graminis, B. sabiae, B. phymatum and B. sartisoli (Fig. 1, and File S2). The 16S rRNA gene sequences for the 12 Burkholderia isolates examined here were on average 95\% similar to that of the type strain (ATCC 25416) of B. cepacia (type species of the genus).

Phylogenetic analysis of the respective $16 \mathrm{~S}$ rRNA, recA, atpD and rpoB datasets allowed recovery of the 12 isolates examined in this study as a single clade (Figs. S1-S4). The concatenated four-gene dataset also clustered these isolates into a single well supported (100\% maximum parsimony and maximum likelihood bootstrap support) clade (Fig. 2). The data clearly showed that this clade never included any of the species with which the 12 isolates share apparently high levels of $16 \mathrm{~S}$ rRNA gene sequence similarity (Fig. 2; Figs. S1-S4). We therefore recognized the clade containing these 12 isolates as a new taxon in the genus (we proposed the name B. kirstenboschensis sp. nov. 


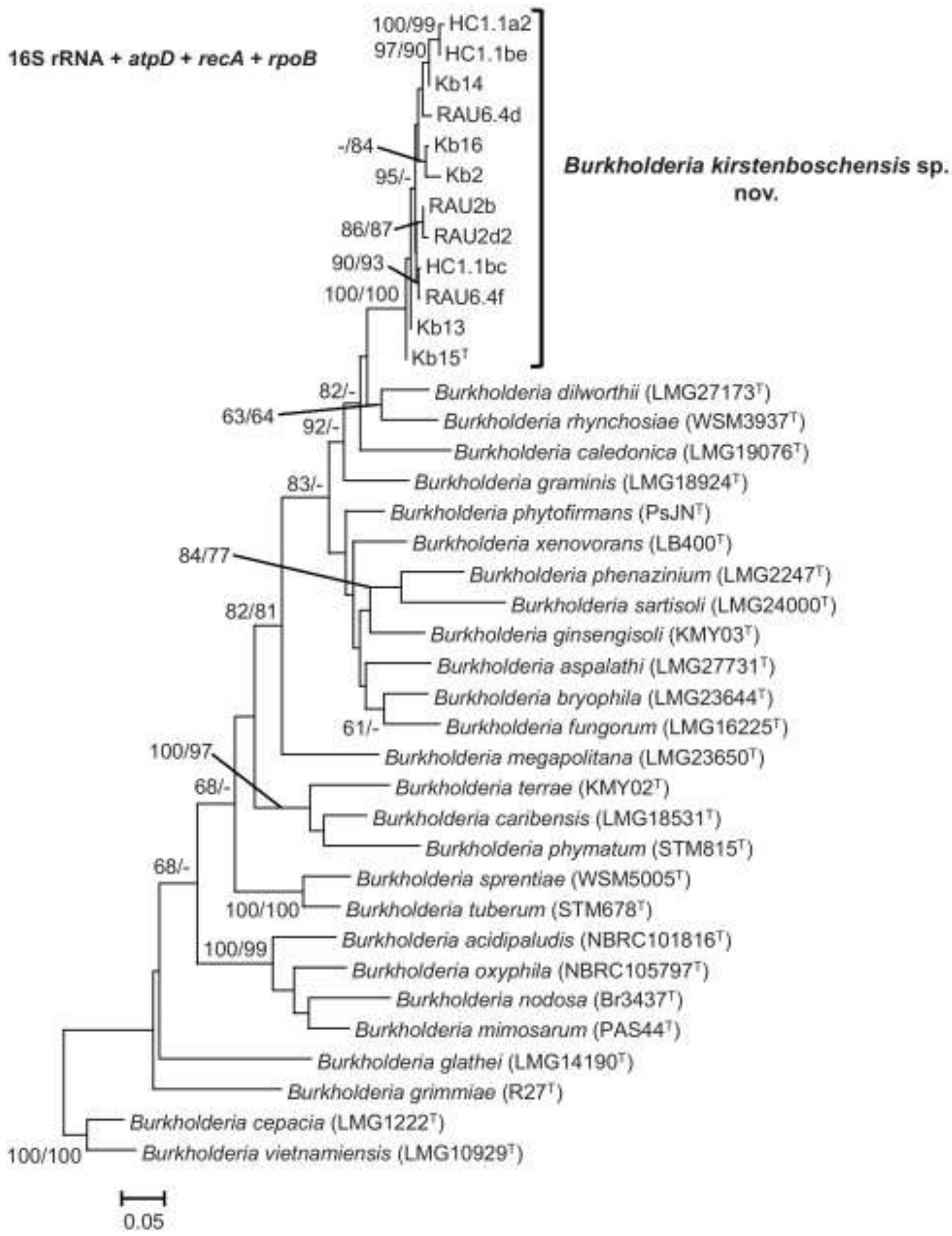

Figure 2. The maximum-likelihood phylogeny inferred from the concatenated data for the genes $16 \mathrm{~S}$ rRNA, $a t p D$, recA and rpoB of Burkholderia kirstenboschensis sp. nov. and related species. The sequences for $B$. cepacia and B. vietnamiensis were used for outgroup purposes. Similar groupings were obtained using maximum parsimony analysis. Bootstrap values $(\geq 60 \%)$ are indicated at the branches in the order maximumlikelihood/parsimony. The type strains for the respective species are indicated in parentheses, and the scale bar indicates the number of nucleotide changes per site. See File S3 for GenBank accession numbers, and Figs. S1-S4 for the individual gene trees. 
for the taxon [see the Discussion] and for simplicity sake we used this designation to refer to the clade in the sections below). Within the larger genus, the new taxon represents a sister taxon of the two South African species, $B$. dilworthii and $B$. rhynchosiae, while it is only distantly related to the other South African species (i.e., $B$. sprentiae, B. tuberum and B. aspalathi).

\subsection{Phenotypic characterization}

All 12 of the isolates examined represented Gram-negative, rod-shaped, motile bacteria (ca. $0.7-2.3 \mu \mathrm{m}$ ). All isolates displayed growth on TYA, TSA and YMA after 24-48 h of incubation at $28{ }^{\circ} \mathrm{C}$. However, colonies were more mucoid on TYA and YMA than on TSA. Only four isolates displayed growth on MA after 4 days of incubation at $29{ }^{\circ} \mathrm{C}$, while growth on MA was observed for only one isolate (RAU2d2) following 4 days of incubation at $37^{\circ} \mathrm{C}$.

Metabolic profile analysis using API 20NE and API 20E strips and the Biolog GN2 MicroPlate system under standardized conditions, allowed differentiation of $B$. kirstenboschensis sp. nov. from the type strains of other Burkholderia species (Table 1), particularly its nearest phylogenetic neighbours B. rhynchosiae and B. dilworthii. These analyses did not include B. cepacia as it is only distantly related to our new taxon. All isolates displayed a positive reaction for the assimilation of adipic acid and a negative reaction for arginine dihydrolase which distinguished B. kirstenboschensis sp. nov. from B. rhynchosiae [24]. A positive reaction for all isolates for acetoin production and negative reactions for arginine dihydrolase, tryptophan deaminase and the oxidation of 
Table 1. Phenotypic traits that differentiate the isolates of $B$. kirstenboschensis sp. nov. from the type strains of related Burkholderia species.

\begin{tabular}{|c|c|c|c|c|c|c|c|c|c|c|c|c|c|}
\hline \multirow[t]{2}{*}{ Phenotypic traits $^{\text {a }}$} & \multicolumn{13}{|c|}{ Burkholderia species ${ }^{b}$} \\
\hline & 1 & 2 & 3 & 4 & 5 & 6 & 7 & 8 & 9 & 10 & 11 & 12 & 13 \\
\hline Isolation source & $\mathrm{RN}$ & $\mathrm{RN}$ & $\mathrm{RH}$ & $\mathrm{RN}$ & $\mathrm{RN}$ & $\mathrm{RN}$ & $\mathrm{RN}$ & $\mathrm{RN}$ & $\mathrm{RN}$ & $\mathrm{RN}$ & $\mathrm{RN}$ & $\mathrm{RN}$ & $\mathrm{RN}$ \\
\hline Nitrate reduction & V & + & + & + & V & + & + & - & + & - & + & - & + \\
\hline \multicolumn{14}{|l|}{ Activity of: } \\
\hline Arginine dihydrolase & + & $+w$ & - & - & - & ND & - & $+w$ & - & + & - & - & - \\
\hline Tryptophan deaminase & + & + & - & ND & ND & ND & - & - & ND & $+w$ & ND & - & ND \\
\hline Urease & V & - & - & + & V & + & - & - & + & - & + & - & - \\
\hline$\beta$-Galactosidase & V & $+{ }^{w}$ & + & + & - & + & + & + & + & + & + & + & + \\
\hline \multicolumn{14}{|l|}{ Assimilation of: } \\
\hline Adipic acid & + & + & - & - & - & + & - & - & - & - & - & - & ND \\
\hline Capric acid & $\mathrm{V}$ & - & + & - & - & + & + & $+{ }^{w}$ & + & - & - & + & + \\
\hline d-Glucose & + & + & + & + & + & + & + & + & + & + & + & + & + \\
\hline d-Mannitol & + & + & + & + & + & + & + & + & + & + & + & + & + \\
\hline d-Mannose & + & + & + & + & + & + & + & + & + & + & + & + & + \\
\hline I-Arabinose & + & + & + & + & V & + & + & + & + & + & + & + & + \\
\hline N-Acetylglucosamine & + & + & + & + & ND & + & + & + & + & + & + & + & + \\
\hline Trisodium citrate & V & + & - & + & - & + & - & + & + & $+w$ & + & ND & + \\
\hline \multicolumn{14}{|l|}{ Fermentation/oxidation of: } \\
\hline d-Glucose & - & $+w$ & - & - & - & - & - & - & - & - & - & - & - \\
\hline
\end{tabular}




\begin{tabular}{|c|c|c|c|c|c|c|c|c|c|c|c|c|c|}
\hline d-Mannitol & - & - & - & + & + & + & + & - & + & - & + & ND & ND \\
\hline d-Sorbitol & - & - & - & + & + & + & + & - & + & - & + & ND & ND \\
\hline Inositol & - & - & - & ND & + & + & ND & - & $+w$ & - & + & ND & ND \\
\hline I-Arabinose & $+{ }^{w}$ & $+{ }^{w}$ & - & + & + & + & ND & - & + & - & + & ND & ND \\
\hline Acetoin production & + & - & ND & ND & ND & ND & ND & $+{ }^{w}$ & ND & ND & ND & ND & ND \\
\hline DNA G+C content (mol\%) & 61.8 & $\begin{array}{c}61.4- \\
61.9\end{array}$ & 62.0 & $63-65$ & 64.8 & 62.8 & 62.1 & 61.2 & 64.5 & 61.6 & $\begin{array}{l}64.2- \\
65.7\end{array}$ & 62.8 & 60.1 \\
\hline
\end{tabular}

a The results of the various properties were coded as follows: $\mathrm{RN}$, root nodule; $\mathrm{RH}$, rhizosphere; + all strains positive; $+{ }^{\mathrm{w}}$, weak positive; - all strains negative; $V$, variable; ND, no data available.

b Isolates and strains are numbered as follows: 1 , B. kirstenboschensis sp. nov. ( $\mathrm{n}=12$; this study); 2, B. dilworthii LMG 27173 ${ }^{\top}$ [24]; 3, B. caledonica LMG

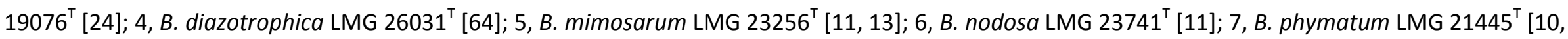
76]; 8, B. rhynchosiae WSM3937 [24]; 9, B. sabiae LMG $24235^{\top}$ [10]; 10, B. sprentiae WSM5005 ${ }^{\top}$ [22]; 11, B. symbiotica JPY345 ${ }^{\top}[65$ ]; 12, B. tuberum LMG $21444^{\top}[24]$; and 13, B. aspalathi $\mathrm{LMG}^{\mathrm{T}} 27731^{\top}[47]$. 
D-glucose distinguished B. kirstenboschensis sp. nov. from B. dilworthii [24]. The complete results of the phenotypic tests are presented in the species description.

\subsection{DNA-DNA hybridization}

The taxa selected for the DNA-DNA hybridization experiments were selected based on the results for the 16S rRNA sequence comparisons, combined with the MLSA and ANI results (see below). This included three (B. caledonica, B. megapolitana and $B$. fungorum) of the five species with the highest $16 \mathrm{~S}$ rRNA sequence similarity $(\geq 98.7 \%)$ to B. kirstenboschensis sp. nov. (i.e., B. phytofirmans and B. bryophila were not included as they shared $<92 \%$ ANI with B. kirstenboschensis sp. nov.). In addition to these three species, the DNA-DNA hybridization experiments also included B. rhynchosiae and $B$. dilworthii, which appears to be the closest known relatives of B. kirstenboschensis sp. nov.

Values between $70.9( \pm 3.7) \%$ and $101.4( \pm 7.2) \%$ were obtained for the intra-species DNA-DNA hybridization experiments conducted with the various isolates of $B$. kirstenboschensis sp. nov. (Fig. 3). The only exception was for the hybridizations involving isolate RAU2d2, specifically where the DNA from this isolate was immobilized on the microplate. This caused the variation observed for reciprocal reactions to fall outside the accepted limits of the method [34]. For example, the respective hybridization reactions between $\mathrm{Kb}^{\mathrm{T}} 5^{\mathrm{T}}$ and RAU2d2 generated an average value of $73 \%$ when $\mathrm{Kb} 15^{\mathrm{T}}$ was immobilized on the microplate and RAU2d2 used as the probe, and an average value of $61.5 \%$ for the reciprocal reaction (i.e., when RAU2d2 was immobilized and $\mathrm{Kb} 15^{\mathrm{T}}$ used as the probe). The average similarity for this pair of strains was therefore $67.2 \%$, with a difference of $11.5 \%$ between reciprocals. This discrepancy 


\section{B. kirstenboschensis sp. nov.}

\begin{tabular}{|c|c|c|c|c|c|c|c|c|c|}
\hline \multirow{3}{*}{ HC1.1a2 } & $\mathrm{HC} 1.1 \mathrm{a} 2$ & HC1.1be & RAU $2 b$ & RAU2d2 & RAU6.4d & RAU6.4f & $\mathrm{Kb} 2$ & $\mathrm{~Kb} 13$ & $\mathrm{~Kb} 15^{\top}$ \\
\hline & 100 & & & & & & & & \\
\hline & $101.4( \pm 7.2)$ & 100 & & & & & & & \\
\hline RAU $2 b$ & ND & ND & 100 & & & & & & \\
\hline RAU2d2 & ND & ND & ND & 100 & & & & & \\
\hline RAU6.4d & ND & ND & $75.4( \pm 5.2)$ & $63.5( \pm 2.0)^{2}$ & 100 & & & & \\
\hline RAU6.4f & ND & ND & ND & ND & ND & 100 & & & \\
\hline $\mathrm{Kb} 2$ & $77.3( \pm 4.2)$ & $74.4( \pm 1.1\}$ & ND & $67.1( \pm 8.6)^{2}$ & ND & ND & 100 & & \\
\hline Kb13 & ND & ND & $70.9( \pm 3.7)$ & $72.3( \pm 12.5)$ & $75.2( \pm 6.9)$ & $80.7( \pm 0.3)$ & $78.3( \pm 5.1)$ & 100 & \\
\hline $\mathrm{Kb} 15^{\mathrm{T}}$ & $81( \pm 6.5)$ & $77.1( \pm 0.5)$ & $82.7( \pm 2.4)$ & $67.2( \pm 5.8)^{3}$ & $79.2( \pm 3.6)$ & $82.6( \pm 4.0)$ & $82.8( \pm 0.7)$ & $100( \pm 10.4)$ & 100 \\
\hline
\end{tabular}

B. dilworthii LMG $27173^{\top}$
B. rhynchosiae LMG $27174^{\top}$.
B. caledonica LMG $19076^{\top}$...
B. megapolitana LMG $23650^{\top}$..
B. fungorum LMG $16225^{\top}$

Figure 3. Percentage DNA-DNA hybridization values amongst isolates of B. kirstenboschensis sp. nov. and the type strains of other Burkholderia species. The values in parentheses indicate the difference between the reciprocal reactions divided by 2 . Where RAU2d 2 with its larger genome was used as the probe in these experiments, the values were typically higher (experiments with such reciprocal reactions values are indicated with Arabic numerals where ${ }^{1}=58.5$ and $75.6 \%{ }^{2}=59.7$ and $84.8 \%{ }^{3}=61.5$

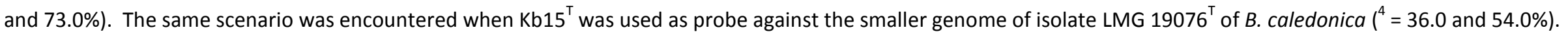


between the reciprocal reactions also generated average values below $70 \%$ when RAU2d2 was hybridized with RAU6.4d and Kb2. In all of these cases, however, the use of RAU2d 2 as the probe generated hybridization values exceeding $70 \%$. The hybridization experiments involving isolates RAU6.4d and $\mathrm{Kb} 13$ followed the same trend. Values below 50\% were obtained for the experiments involving B. kirstenboschensis sp. nov. isolate $\mathrm{Kb}^{\mathrm{T}} 5^{\mathrm{T}}$ and the type strains for any one of $B$. fungorum, B. caledonica, $B$. megapolitana, B. rhynchosiae and B. dilworthii included in the comparison.

\subsection{Genome sequences for isolates $\mathrm{Kb}^{1} 5^{\mathrm{T}}$ and RAU2d2}

A total of 5010566 single-ended reads were generated for B. kirstenboschensis sp. nov. isolate $\mathrm{Kb} 15^{\mathrm{T}}$. After application of the quality filter, 4190410 reads with an average length of 219 bases were assembled into a draft genome consisting of 8342886 bases. The draft genome assembly of isolate $\mathrm{Kb}^{\mathrm{T}}$ consisted of 973 contigs with $109 \mathrm{x}$ coverage, and it had an N50 of 15997 bases and G + C content of 61.84 mol\%. The draft genome assembly sequence is available from the National Centre for Biotechnology Information (NCBI: http://www.ncbi.nlm.nih.gov/) under the accession number JRZC00000000.

A total of 4733415 reads were generated for B. kirstenboschensis sp. nov. isolate RAU2d2. After quality filtering, the remaining 3199998 pair-ended reads (average length of 214 bases) were assembled into a draft genome consisting of 9150776 bases. The draft genome sequence of isolate RAU2d2 consisted of 1182 contigs with $74 \mathrm{x}$ coverage, N50 of 14028 bases and G + C content of 61.64 mol\%. The draft genome 
sequence for the isolate was submitted to the NCBI database under the accession number JRTU00000000.

Analysis of the shared genomic regions between isolates $\mathrm{Kb}^{\mathrm{T}} 5^{\mathrm{T}}$ and RAU2d2 showed that each strain contained long stretches of apparently unique DNA. Of the 8342886 bases in $\mathrm{Kb} 15^{\mathrm{T}}$, only about $84 \%$ aligned to the genome of isolate RAU2d2 with the remaining 16\% (approximately $1.3 \mathrm{Mb}$ ) not shared with RAU2d2. Similarly, only 77\% of the RAU2d2 genome sequence aligned to that of $\mathrm{Kb}^{\mathrm{T}} \mathrm{T}^{\mathrm{T}}$, with the remaining $23 \%$ (approximately 2.1 Mb) unique to RAU2d2.

The genomes of isolates $\mathrm{Kb} 15^{\mathrm{T}}$ and RAU2d2 were predicted to respectively encode 8688 and 9869 ORFs. In both cases, about a third of the ORFs could be analysed using the FIGfams database (the remaining ORFs were either annotated as "hypothetical genes" or had annotations for which suitable Subsystem categories are not available; see Fig. S5). Comparison of the annotations for the ORFs of isolates $\mathrm{Kb}^{\mathrm{T}} \mathrm{5}^{\mathrm{T}}$ and RAU2d2 revealed putative differences in the metabolic capabilities and functional pathways they encode (Table 2). These differences included the presence of the MazEF toxin-antitoxin system in RAU2d2 with its larger genome [82]. Comparison of the FIGfam Subsystems categories identified from the genomes of B. kirstenboschensis sp. nov., B. dilworthii and B. caledonica further allowed identification of processes or pathways potentially unique to B. kirstenboschensis sp. nov. (Table 2). For example, isolates $\mathrm{Kb}^{\mathrm{T}} \mathrm{5}^{\mathrm{T}}$ and RAU2d2 both appear to encode the full pathway for tricarballylate utilization [43]. 
Table 2. FIGfams Subsystem categories predicted to be differentially encoded by the genomes of $B$. kirstenboschensis sp. nov., B. dilworthii LMG $27173^{\top}$ and $B$. caledonica LMG $19076^{\top}$.

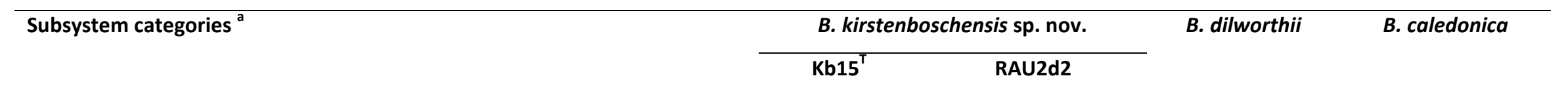

Polymorphic categories in B. kirstenboschensis sp. nov.

Arsenic resistance repressor

Toluene degradation

- Toluenesulfonate zinc-independent alcohol dehydrogenase

Toxin-antitoxin MT1 system

- Toxin 1, PIN domain

- vapC, Toxin-antitoxin replicon stabilization systems

MazEF-like toxin-antitoxin system (All genes)

- chpS, programmed cell death antitoxin

- peml, programmed cell death antitoxin

- chpB, programmed cell death toxin

Succinate dehydrogenase

- Fumarate reductase flavoprotein subunit

- Flavoprotein(N-terminal) FAD-dependent oxidoreductase

Categories that distinguish B. kirstenboschensis sp. nov.

Tricarballylate utilization (full pathway)

$-\operatorname{tcu} A$

$-t c u B$ 
- tcuC
- tcuR
Cinnamic acid degradation
- mphA
- $m p h E$
- mph operon transcriptional activator

Tellurite resistance

- tehA

Zinc resistance

- Response regulator of zinc $\sigma$-54-dependent two-

component system

Denitrification

- Respiratory nitrate reductase alpha chain

- Respiratory nitrate reductase beta chain

- Respiratory nitrate reductase delta chain

- Respiratory nitrate reductase gamma chain

Cyanate hydrolysis

- Cyanate hydratase

- Cyn operon transcriptional activator

Dye-decolorizing peroxidase DyP
$+$

$+$

$+$

$\begin{array}{cccc}- & + & - \\ - & + & - \\ - & + & - \\ - & + & + \\ - & - & + \\ - & - & +\end{array}$

${ }^{a}$ The FIGfams Subsystem categories was described by Meyer et al. [49]. FIGfams represent sets of homologous protein sequences where each set likely represent isofunctional homologs. Each Subsystem category reflects a process/phenotype (e.g., Tricarballylate utilization) that is underpinned by a set of genes (e.g., tcuA, tcuB, tcuC and $t c u D$ ) whose products contribute to, or, make up the process/ phenotype; + genes present; - genes absent. 
B. kirstenboschensis sp. nov. (Kb15 $\left.{ }^{\mathrm{T}}\right)$

\begin{tabular}{|c|c|c|c|c|c|c|c|c|c|c|c|}
\hline \\
\hline
\end{tabular}

Figure 4. Pairwise comparison of the percentage Average Nucleotide Identity (ANI) shared amongst B. kirstenboschensis sp. nov. and related Burkholderia species for which whole genome sequences are available. In all these cases, the analyzed genomes represented those for the type strains of the various species available from public domain databases (GenBank Accession numbers GCA_000472525.1, GCA_000172415.1, GCA_000416445.1, GCA_000685095.1, GCA_000756045.1, GCA_000020125.1, GCA_000685055.1 and GCA_000473465.1, and Gold Project ID Gp0001007). The only exceptions were B. kirstenboschensis isolate RAU2d2 (this study; JRTU00000000) and B. bryophila for which the sequence for strain BR3495a were utilized (GCA_000383275.1). The analyses were conducted with JSpecies [59], which involved artificial shearing of the respective genomes into 1020-nucleotide fragments that were then compared using the BLAST algorithm [33, 59]. Reciprocal search results are indicated above and below the diagonal. 


\subsection{Average nucleotide identities}

The ANI-values for B. kirstenboschensis sp. nov. isolates $\mathrm{Kb}^{\mathrm{T}} \mathrm{5}^{\mathrm{T}}$ and RAU2d2 exceeded 96\% (Fig. 4). The ANI-values estimated from all experiments involving comparisons with other Burkholderia species (including the closely related B. dilworthii) were all well below $90 \%$ (i.e., the accepted cut off value for species is $\geq 96 \% ; 33,59$ ). The only exceptions were the comparisons involving both isolates $\mathrm{Kb}^{1} 5^{\mathrm{T}}$ and RAU2d2 with $B$. caledonica and B. bryophila, which generated values of 91.3-92.7\%.

\section{Discussion}

The results of this study indicated that the 12 Burkholderia isolates examined represent a unique and exclusive group of rhizobial individuals. This group was unlike any known Burkholderia species and was recovered as monophyletic using all four of the housekeeping genes, irrespective of whether the gene sequences were concatenated or analyzed individually. Such genealogical exclusivity and concordance among multiple independent loci are both hallmarks of a species $[19,66]$. The 12 Burkholderia isolates examined were therefore regarded as conspecific (i.e., they represent members of the same species), because all of the isolates were more closely related to each other than to any other known isolate or species of Burkholderia. We accordingly recognized the group of 12 Burkholderia isolates examined here as a new species in the genus.

The existence of the newly proposed species taxon was supported by all other aspects of the polyphasic approach utilized to delineate this taxon. These included intra-specific DNA-DNA hybridization and ANI-values that exceeded $70 \%$ and $96 \%$ respectively. All comparisons involving isolates of the new taxon with any other Burkholderia species 
yielded values much lower than those typically used as the lower limits for demarcating species $[31,39,59,68]$. The high level of genetic cohesion observed among isolates of the new taxon was also reflected at the phenotypic level, as they exhibited similar metabolic profiles. Several of the metabolic properties investigated also allow differentiation of the new taxon from closely related South African species capable of nodulating legumes (i.e., $B$. rhynchosiae and $B$. dilworthii) [24]. The name $B$. kirstenboschensis sp. nov. was accordingly proposed for this new assemblage of rootnodule symbionts from Hypocalyptus spp. and V. oroboides growing in the CRF of South Africa.

Despite the obligatory inclusion of $16 \mathrm{~S}$ rRNA sequence information in most descriptions of bacterial species $[31,68]$, the value of this gene for taxonomically defining new or unique Burkholderia species is exceedingly limited. As currently circumscribed, the genus includes roughly 88 species of which 17 have $16 \mathrm{~S}$ rRNA sequences that are $\geq 97 \%$ similar to one or more of the B. kirstenboschensis sp. nov. isolates examined in this study. These 17 species include ecologically diverse taxa ranging from root-nodulaters (e.g., B. dilworthii and B. rhynchosiae) $[23,24]$ and moss-associated species such as $B$. megapolitana and $B$. bryophila [77] through to environmental species such as $B$. xenovorans [32]. In fact, the species with $16 \mathrm{~S}$ rRNA sequences most similar to that of $B$. kirstenboschensis sp. nov. is B. fungorum, which in addition to having been reported from root nodules has also been recovered from fungal and clinical specimens $[17,18]$. Even in combination with ecological data, $16 \mathrm{~S}$ rRNA sequences thus have little value in diagnosing these species. Even based on a higher similarity value of $\geq 98.7 \%$ [67], five of these species were still more similar to one or more of the B. kirstenboschensis sp. nov. isolates. The limited potential of this marker for resolving Burkholderia species has 
been noted before [75] and our data support suggestions that the absolute necessity of 16S rRNA information for describing species should be revised and/or replaced with more robust and taxonomically meaningful data $[15,51,59,75]$.

The results of our study showed that the members of B. kirstenboschensis sp. nov. can differ markedly in terms of the size of their genomes. Although the genomes of the two isolates examined differed by approximately $0.81 \mathrm{Mb}$, such intra-specific differences are not uncommon among bacteria [41, 44, 63]. However, both the B. kirstenboschensis sp. nov. isolates appeared to be characterized by relatively large amounts of seemingly unique DNA. As much as $2.1 \mathrm{Mb}(23 \%)$ of the DNA of isolate RAU2d2 did not align to the genome sequence of isolate $\mathrm{Kb} 15^{\mathrm{T}}$, while $1.3 \mathrm{Mb}(16 \%)$ of the $\mathrm{Kb}^{15^{\mathrm{T}}}$ genome did not align to that of RAU2d2. This lack of conservation in genome content at the intraspecific level thus suggest that the unique genomic regions represent part of the taxon's accessory or dispensable genome $[40,48]$. For these isolates, the remaining $77-84 \%$ of their genome content likely comprises the core genome of the species $[40,48]$, which is similar to what has been reported for species such as Streptococcus pyogenes [41], Neisseria meningitides [63] and Pantoea ananatis [21].

Our findings further indicate that genome size differences can have a significant effect on the outcome of DNA-DNA hybridization experiments. This applies specifically to the associated differences between reciprocal reactions, which is consistent with what has been suggested before [9]. Although most of the DNA-DNA hybridization values estimated for B. kirstenboschensis sp. nov. were within the range of what is expected for well-delineated species, the values obtained with isolate RAU2d2 with its large $9.1 \mathrm{Mb}$ genome were typically problematic (see Fig. 3). For example, hybridizations using DNA 
from isolate RAU2d2 as probe yielded higher values than when a smaller genome was used as the probe in the reverse reaction. Likewise, Goris et al. [33] reported a significant linear correlation between the difference in reciprocal DNA-DNA hybridization values and the difference in the percentage of conserved DNA between two genomes. Although they utilized an extensive set of species and isolates, none of their experimental sets were directly comparable to those reported for $B$. kirstenboschensis sp. nov. in terms of genome size differences within the same species. We therefore concur with their conclusion that in most cases "DNA-DNA hybridization is too coarse a method (i.e. the experimental error is too high) to reveal subtle differences in genome size between strains", but emphasize that large genome differences among conspecifics can significantly influence the outcome of DNA-DNA hybridization experiments.

Taken together the findings presented in this study suggest that the criteria for delineating and describing new Burkholderia species require considerable refinement and/or revision. This echoes previous calls for an overhaul of the current standards for species descriptions [57, 78]. By making use of B. kirstenboschensis sp. nov. we have clearly illustrated the consequences of substantial genome size differences for DNADNA hybridization experiments. The prerequisite inclusion of DNA-DNA hybridization data therefore has little scientific merit in this case, especially in view of the current explosion in genome information for Burkholderia and other bacteria (e.g., see Whitman et al. [81] and the Genomes Online Database [https://gold.jgi-psf.org/]). In fact, our application of ANI as a genomic metric based on shared genome content, was more useful for showing genomic cohesion in B. kirstenboschensis sp. nov. This is in agreement with the fact that ANI is widely regarded to robustly reveal genomic 
coherence among members of the same species $[39,51,59]$. Although current gene ontology databases are still somewhat limited (e.g., functions have not been linked to all known gene sequences and new genomes often contain gene sequences new to Science), our data suggests that the analysis of the genomic components unique to species and specific isolates likely holds valuable clues regarding their repertoires of biological capabilities under natural conditions. Substitution of DNA-DNA hybridization data with the use of genome sequence data as a prerequisite for the description of Burkholderia species will thus not only speed up the pace at which bacterial diversity is documented, but also allow access to the information that provides the genetic "blue print" for the species.

\subsection{Description of B. kirstenboschensis sp. nov.}

Burkholderia kirstenboschensis (kir.sten.bosch.en'sis. N.L. fem. adj. kirstenboschensis of Kirstenbosch, a botanical garden in South Africa, from where the type strain was isolated).

Cells are Gram-negative, motile, straight rods (ca. 0.7 x $2.3 \mu \mathrm{m})$. Positive for oxidase and catalase. Colonies are round, creamy white to yellowish and 1-2 $\mathrm{mm}$ in size on TYA. Isolates from Virgilia oroboides have simple rough surfaces, while other isolates have smooth surfaces. Growth occurs on TYA, TSA and YMA at $28{ }^{\circ} \mathrm{C}$. Positive for growth in Tryptone Yeast Broth with $0.5 \%$ and $1 \% \mathrm{NaCl}$. Positive for the production of acetoin and arginine dihydrolase and the hydrolysis of Tween 40 and Tween 80 . Positive for the assimilation of D-glucose, L-arabinose, D-mannose, D-mannitol, $N$-acetyl-glucosamine, potassium gluconate, adipic acid, malic acid and phenylacetic acid. Additionally, positive reactions are recorded for the assimilation of adonitol, D-arabitol, D-fructose, Lfructose, D-galactose, $\alpha$-D-glucose, L-rhamnose, D-sorbitol, D-trehalose, methyl 
pyruvate, mono-methyl-succinate, acetic acid, cis-aconitic acid, formic acid, D-gluconic acid, D-glucosaminic acid, $\alpha$-hydroxy butyric acid, $\rho$-hydroxy phenylacetic acid, D,Llactic acid, propionic acid, quinic acid, D-saccharic acid, succinic acid, bromo succinic acid, succinamic acid, D-alanine, L-alanine, L-aspargine, L-aspartic acid, L-glutamic acid, L-proline, L-pyroglutamic acid, D-serine, L-serine and L-threonine. Negative reactions are recorded for arginine dihydrolase, lysine decarboxylase, ornithine decarboxylase, $\mathrm{H}_{2} \mathrm{~S}$ production, tryptophan deaminase, indole production, $\beta$-glucosidase activity, the assimilation of D-maltose and the fermentation/oxidation of D-glucose, the oxidation of D-mannitol, inositol, D-sorbitol, D-sucrose and amygdalin. Additional negative reactions are recorded for the assimilation of $\alpha$-cyclodextrin, dextrin, glycogen, $N$-acetyl-Dgalactosamine, i-erythritol, gentiobiose, $\alpha$-D-lactose, maltose, D-melibiose, $\beta$-methyl-Dglucoside, D-psicose, turanose, xylitol, itaconic acid, $\alpha$-keto valeric acid, glycyl-L-aspartic acid, L-ornithine, uridine, thymidine, phenyethylamine, putrescine, 2,3-butanediol and glucose-1-phosphate.

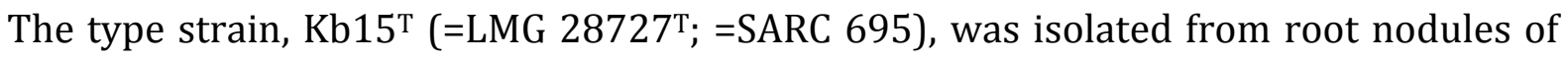
Virgilia oroboides from the Western Cape of South Africa. The DNA G + C content of the type strain is $61.8 \mathrm{~mol} \%$ as determined by whole genome sequencing.

\section{Acknowledgements}

We dedicate this paper to the late Ms. Jacomina Bloem; who was responsible for the collection of the Virgilia isolates from Kirstenbosch National Botanical Garden in her capacity as researcher at the Agricultural Research Council of South Africa. We are grateful to the South African National Research Foundation (NRF) and the Department of Science and Technology for funding through their Centre of Excellence programme. 
We would also like to acknowledge the Bioinformatics and Computational Biology Unit of the University of Pretoria, for the use of their computational infrastructure.

\section{References}

[1] Altschul, S.F., Madden, T.L., Schäffer, A.A., Zhang, J., Zhang, Z., Miller, W., Lipman, D.J. (1997) Gapped BLAST and PSI-BLAST: a new generation of protein database search programs. Nucleic Acids Res. 25, 3389-3402.

[2] Aziz, R.K., Bartels, D., Best, A.A., DeJongh, M., Disz, T., Edwards, R.A., Formsma, K., Gerdes, S., Glass, E.M., Kubal, M., Meyer, F., Olsen, G.J., Olson, R., Osterman, A.L., Overbeek, R.A., McNeil, L.K., Paarmann, D., Paczian, T., Parrello, B., Pusch, G.D., Reich, C., Stevens, R., Vassieva, O., Vonstein, V., Wilke, A., Zagnitko, O. (2008) The RAST Server: Rapid Annotations using Subsystems Technology. BMC Genomics 9, 75. doi:10.1186/1471-2164-9-75.

[3] Baldwin, A., Mahenthiralingam, E., Thickett, K.M., Honeybourne, D., Maiden, M. C., Govan, J.R., Speert, D.P., LiPuma, J.J., Vandamme, P., Dowson, C.G. (2005) Multilocus sequence typing scheme that provides both species and strain differentiation for the Burkholderia cepacia complex. J. Clin. Microbiol. 43, 4665-4673.

[4] Barrett, C.F., Parker, M.A. (2006) Coexistence of Burkholderia, Cupriavidus, and Rhizobium sp. nodule bacteria on two Mimosa spp. in Costa Rica. Appl. Environ. Microbiol. 72, 1198-1206.

[5] Beukes, C.W., Venter, S.N., Law, I.J., Phalane, F.L., Steenkamp, E.T. (2013) South African Papilionoid legumes are nodulated by diverse Burkholderia with unique nodulation and nitrogen-fixation loci. PLoS ONE 8(7): e68406. doi:10.1371/journal.pone.0068406

[6] Blankenberg, D., Gordon, A., Von Kuster, G., Coraor, N., Taylor, J., Nekrutenko, A. and the Galaxy Team (2010) Manipulation of FASTQ data with Galaxy. Bioinformatics 26, 1783-1785. 
[7] Bontemps, C., Elliott, G.N., Simon, M.F., Dos Reis Júnior, F.B., Gross, E., Lawton, R.C., Neto, N.E., de Fátima Loureiro, M., de Faria, S.M., Sprent, J.I., James, E.K., Young, J.P.W. (2010) Burkholderia species are ancient symbionts of legumes. Mol. Ecol. 19, 44-52.

[8] Bournaud, C., de Faria, S.M., dos Santos, J.M.F., Tisseyre, P., Silva, M., Chaintreuil, C., Gross, E., James, E.K., Prin, Y., Moulin, L. (2013) Burkholderia species are the most common and preferred nodulating symbionts of the Piptadenia group (Tribe Mimoseae). PLoS ONE 8(5): e63478. doi: 10.1371/journal.pone.0063478

[9] Brenner, D.J. (1978) Characterization and clinical identification of Enterobacteriaceae by DNA hybridization. Prog. Clin. Pathol. 7,71-117

[10] Chen, W-M., de Faria, S.M., Chou, J-H., James, E.K., Elliott, G.N., Sprent, J.I., Bontemps, C., Young, J.P.W., Vandamme, P. (2008) Burkholderia sabiae sp. nov., isolated from root nodules of Mimosa caesalpiniifolia. Int. J. Syst. Evol. Microbiol. 58, 2174-2179.

[11] Chen, W-M., de Faria, S.M., James, E.K., Elliott, G.N., Lin, K-Y., Chou, J-H., Sheu, S-Y., Cnockaert, M., Sprent, J.I., Vandamme, P. (2007) Burkholderia nodosa sp. nov., isolated from root nodules of the woody Brazilian legumes Mimosa bimucronata and Mimosa scabrella. Int. J. Syst. Evol. Microbiol. 57, 1055-1059.

[12] Chen, W-M., de Faria, S.M., Straliotto, R., Pitard, R.M., Simões-Araùjo, J.L., Chou, J-H., Chou, Y-J., Barrios, E., Prescott, A.R., Elliott, G.N., Sprent, J.I., Young, J.P.W., James, E.K. (2005) Proof that Burkholderia strains form effective symbioses with legumes: a study of novel Mimosa-nodulating strains from South America. Appl. Environ. Microbiol. 71, 7461-7471.

[13] Chen, W-M., James, E.K., Coenye, T., Chou, J-H., Barrios, E., de Faria, S.M., Elliott, G.N., Sheu, S-Y., Sprent, J.I., Vandamme, P. (2006) Burkholderia mimosarum sp. nov., isolated from root nodules of Mimosa spp. from Taiwan and South America. Int. J. Syst. Evol. Microbiol. 56, 1847-1851. 
[14] Chiaromonte, F., Yap, V.B., Miller, W. (2002) Scoring pairwise genomic sequence alignments. Pac. Symp. Biocomput. 115-126.

[15] Chun, J., Rainey, F.A. (2014) Integrating genomics into the taxonomy and systematics of the Bacteria and Archaea. Int. J. Syst. Evol. Microbiol. 64, 316-324.

[16] Cleenwerck, I., Vandemeulebroecke, K., Janssens, D., Swings, J. (2002) Re-examination of the genus Acetobacter, with descriptions of Acetobacter cerevisiae sp. nov. and Acetobacter malorum sp. nov. Int. J. Syst. Evol. Microbiol. 52, 1551-1558.

[17] Coenye, T., Laevens, S., Willems, A., Ohlén, M., Hannant, W., Govan, J.R.W., Gillis, M., Falsen, E., Vandamme, P. (2001) Burkholderia fungorum sp. nov. and Burkholderia caledonica sp. nov., two new species isolated from the environment, animals and human clinical samples. Int. J. Syst. Evol. Microbiol. 51, 1099-1107.

[18] Coenye, T., Vandamme, P. (2003) Diversity and significance of Burkholderia species occupying diverse ecological niches. Environ. Microbiol. 5, 719-729.

[19] Coyne, J.A., Orr, H.A. (2004) Speciation. Sinauer Associates, Inc. Sunderland, Massachusettes.

[20] Darling, A.C., Mau, B., Blattner, F.R., Perna, N.T. (2004) Mauve: multiple alignment of conserved genomic sequence with rearrangements. Genome research 14, 1394-1403.

[21] De Maayer, P., Chan, W.Y., Rubagotti, E., Venter, S.N., Toth, I.K., Birch, P.R., Coutinho, T.A. (2014) Analysis of the Pantoea ananatis pan-genome reveals factors underlying its ability to colonize and interact with plant, insect and vertebrate hosts. BMC Genomics 15, 404.

[22] De Meyer, S.E., Cnockaert, M., Ardley, J.K., Maker, G., Yates, R., Howieson, J.G., Vandamme, P. (2013a) Burkholderia sprentiae sp. nov., isolated from Lebeckia ambigua root nodules. Int. J. Syst. Evol. Microbiol. 63, 3950-3957. 
[23] De Meyer, S.E., Cnockaert, M., Ardley, J.K., Trengove, R.D., Garau, G., Howieson, J.G., Vandamme, P. (2013b) Burkholderia rhynchosiae sp. nov., isolated from Rhynchosia ferulifolia root nodules. Int. J. Syst. Evol. Microbiol. 63, 3944-3949.

[24] De Meyer, S.E., Cnockaert, M., Ardley, J.K., Van Wyk, B-E., Vandamme, P.A., Howieson, J.G. (2014) Burkholderia dilworthii sp. nov., isolated from Lebeckia ambigua root nodules. Int. J. Syst. Evol. Microbiol. 64, 1090-1095.

[25] Elliott, G.N., Chen, W-M., Bontemps, C., Chou, J-H., Young, J.P.W., Sprent, J.I., James, E.K. (2007) Nodulation of Cyclopia spp. (Leguminosae, Papilionoideae) by Burkholderia tuberum. Ann. Bot. 100, 1403-1411.

[26] Euzéby, J.P. (1997) List of bacterial names with standing in nomenclature: a folder available on the internet. Int. J. Syst. Bacteriol. 47, 591-592.

[27] Felsenstein, J. (1985) Confidence limits on phylogenies: An approach using the bootstrap. Evolution 39, 783-791.

[28] Felsenstein, J. (2005) PHYLIP (Phylogeny Inference Package) version 3.6. Distributed by the author. Department of Genome Sciences, University of Washington, Seattle (USA). http://evolution.genetics.washington.edu/phylip.html.

[29] Ferreira, P.A.A., Bomfeti, C.A., Soares, B.L., de Souza Moreira, F.M. (2012) Efficient nitrogen-fixing Rhizobium strains isolated from amazonian soils are highly tolerant to acidity and aluminium. World J. Microbiol. Biotechnol. 28, 1947-1959.

[30] Garrity, G.M., Bell, J.A., Linburn, T. (2005). Family I. Burkholderiaceae. In Bergey's Manual of Systematic Bacteriology, $2^{\text {nd }}$ ed., vol. 2, pp. 438-475. Edited by D.J. Brenner, N.R. Krieg, J.T. Staley \& G.M. Garrity. New York: Springer. 
[31] Gevers, D., Cohan, F.M., Lawrence, J.G., Spratt, B.G., Coenye, T., Feil, E.J., Stackebrandt, E., Van de Peer, Y., Vandamme, P., Thompson, F.L., Swings, J. (2005) Opinion: re-evaluating prokaryotic species. Nat. Rev. Microbiol. 3, 733-739.

[32] Goris, J., De Vos, P., Caballero-Mellado, J., Park, J., Falsen, E., Quensen, J. F., III, Tiedje, J. M. \& Vandamme, P. (2004) Classification of the biphenyl- and polychlorinated biphenyl-degrading strain LB400 ${ }^{\mathrm{T}}$ and relatives as Burkholderia xenovorans sp. nov. Int. J. Syst. Evol. Microbiol. 54, 1677-1681.

[33] Goris, J., Konstantinidis, K.T., Klappenbach, J.A., Coenye, T., Vandamme, P., Tiedje, J. M. (2007) DNADNA hybridization values and their relationship to whole-genome sequence similarities. Int. J. Syst. Evol. Microbiol. 57, 81-91.

[34] Goris, J., Suzuki, K., De Vos, P., Nakase, T., Kersters, K. (1998) Evaluation of a microplate DNA-DNA hybridization method compared with the initial renaturation method. Can. J. Microbiol. 44, 11481153.

[35] Guindon, S., Gascuel, O. (2003) A simple, fast and accurate method to estimate large phylogenies by maximum-likelihood. Syst. Biol. 52, 696-704.

[36] Gyaneshwar P., Hirsch, A.M., Moulin, L., Chen, W-M., Elliott, G.N., Bontemps, C., Estrada-de los Santos, P., Gross, E., dos Reis, Jr., F.B., Sprent, J.I., Young, J.P.W., James, E.K. (2011) Legume-nodulating betaproteobacteria: diversity, host range, and future prospects. Mol. Plant-Microbe Interact. 24, 1276-1288.

[37] Hall, T.A. (1999) BioEdit: a user-friendly biological sequence alignment editor and analysis program for Windows 95/98/NT. Nucleic Acids Symp. Ser. 41, 95-98. 
[38] Katoh, K., Toh, H. (2008) Improved accuracy of multiple ncRNA alignment by incorporating structural information into a MAFFT-based framework. BMC Bioinf. 9:212. doi: 10.1186/1471-21059-212

[39] Konstantinidis, K.T., Tiedje, J.M. (2006) Toward a more robust assessment of intraspecies diversity, using fewer genetic markers. Appl. Environ. Microbiol. 72, 7286-7293.

[40] Lan, R., Reeves, P.R. (2000) Intraspecies variation in bacterial genomes: the need for a species genome concept. Trends Microbiol. 8, 396-401.

[41] Lefébure, T., Stanhope, M.J. (2007) Evolution of the core and pan-genome of Streptococcus: positive selection, recombination, and genome composition. Genome Biol. 8, 71 .

[42] Lemaire, B., Dlodlo, O., Chimphango, S., Stirton, C., Schrire, B., Boatwright, J.S., Honnay, O., Smets, E., Sprent, J., James, E.K., Muasya, A.M. (2014) Symbiotic diversity, specificity and distribution of rhizobia in native legumes of the Core Cape Subregion (South Africa). FEMS Microbiol. Ecol. doi: http://dx.doi.org/10.1093/femsec/fiu024

[43] Lewis, J. A., Horswill, A.R., Schwem, B.E., Escalante-Semerena, J.C. (2004) The tricarballylate utilization (tcuRABC) genes of Salmonella enterica serovar Typhimurium LT2. J. Bacteriol. 186, 16291637.

[44] Lukjancenko, O., Wassenaar, T., Ussery, D. (2012) Comparison of 61 sequenced Escherichia coli genomes. Microb. Ecol. 60, 708-720.

[45] Margulies, M., Egholm, M., Altman, W.E., Attiya, S., Bader, J.S., Bemben, L.A., Berka, J., Braverman, M.S., Chen, Y-J., Chen, Z., Dewell, S.B., Du, L., Fierro, J.M., Gomes, X.V., Godwin, B.C., He, W., Helgesen, S., Ho, C.H., Irzyk, G.P., Jando, S.C., Alenquer, M.L., Jarvie, T.P., Jirage, K.B., Kim, J-B., Knight, J.R., Lanza, J.R., Leamon, J.H., Lefkowitz, S.M., Lei, M., Li, J., Lohman, K.L., Lu, H., Makhijani, V.B., McDade, K.E., McKenna, M.P., Myers, E.W., Nickerson, E., Nobile, J.R., Plant, R., Puc, B.P., Ronan, M.T., Roth, G.T., 
Sarkis, G.J., Simons, J.F., Simpson, J.W., Srinivasan, M., Tartaro, K.R., Tomasz, A., Vogt, K.A., Volkmer, G.A., Wang, S.H., Wang, Y., Weiner, M.P., Yu, P., Begley, R.F., Rothberg, J.M. (2005) Genome sequencing in microfabricated high-density picolitre reactors. Nature 437, 376-380.

[46] Martínez-Aguilar, L., Salazar-Salazar, C., Díaz Méndez, R., Caballero-Mellado, J., Hirsch, A.M., VásquezMurrieta, M.S., Estrada-de los Santos, P. (2013) Burkholderia caballeronis sp. nov., a nitrogen fixing species isolated from tomato (Lycopersicon esculentum) with the ability to effectively nodulate Phaseolus vulgaris. Antonie van Leeuwenhoek 104, 1063-1071.

[47] Mavengere, N.R., Ellis, A.G., Le Roux, J.J. (2014) Burkholderia aspalathi sp. nov., isolated from root nodules of the South African legume Aspalathus abietina Thunb. Int. J. Syst. Evol. Microbiol. 64, 19061912.

[48] Medini, D., Donati, C., Tettelin, H., Masignani, V., Rappuoli, R. (2005) The microbial pan-genome. Curr. Opin. Genet. Dev. 15, 589-94.

[49] Meyer, F., Overbeek, R., Rodriguez, A. (2009) FIGfams: yet another set of protein families. Nucleic Acids Res. 37, 6643-6654. http://doi.org/10.1093/nar/gkp698

[50] Nei, M., Kumar, S. (2000) Molecular evolution and phylogenetics. Oxford University Press, New York.

[51] Ormeño-Orrillo, E., Servín-Garcidueñas, L.E., Rogel, M.A., González, V.,Peralta, H., Mora, J., MartínezRomero, J., Martínez-Romero, E. (2015) Taxonomy of rhizobia and agrobacteria from the Rhizobiaceae family in light of genomics. Syst. Appl. Microbiol. doi: dx.doi.org/10.1016/j.syapm.2014.12.002

[52] Overbeek, R., Olson, R., Pusch, G.D., Olsen, G.J., Davis, J.J., Disz, T., Edwards, R.A., Gerdes, S., Parrello, B., Shukla, M., Vonstein, V., Wattam, A.R., Xia, F., Stevens, R. (2014) The SEED and the Rapid Annotation of microbial genomes using Subsystems Technology (RAST). Nucleic Acids Res. 42, D206-214. doi: 10.1093/nar/gkt1226 
[53] Parker, M.A., Wurtz, A.K., Paynter, Q. (2007) Nodule symbiosis of invasive Mimosa pigra in Australia and in ancestral habitats: a comparative analysis. Biol. Invasions 9, 127-138.

[54] Parte, A.C. (2013) LPSN - list of prokaryotic names with standing in nomenclature. Nucleic Acids Res. 42, D613- D616. doi: 10.1093/nar/gkt1111

[55] Pitcher, D.G., Saunders, N.A., Owen, R.J. (1989) Rapid extraction of bacterial genomic DNA with guanidium thiocyanate. Lett. Appl. Microbiol. 8, 151-156. doi: 10.1111/j.1472-765X.1989.tb00262.x

[56] Posada, D. (2008) jModelTest: phylogenetic model averaging. Mol. Biol. Evol. 25, 1253-1256.

[57] Ramasamy, D., Mishra, A.K., Lagier, J-C., Padhmanabhan, R., Rossi, M., Sentausa, E., Raoult, D., Fournier, P-E. (2014) A polyphasic strategy incorporating genomic data for the taxonomic description of novel bacterial species. Int. J. Syst. Evol. Microbiol. 64, 384-391.

[58] Reis, V.M., Estrada de los Santos, P., Tenorio-Salgado, S., Vogel, J., Stoffels, M., Guyon, S., Mavingui. P., Baldani, V.L.D., Schmid, M., Baldani, J.I., Balandreau, J., Hartmann, A., Caballero-Mellado, J. (2004) Burkholderia tropica sp. nov., a novel nitrogen-fixing, plant-associated bacterium. Int. J. Syst. Evol. Microbiol. 54, 2155-2162.

[59] Richter, M., Rosselló-Móra, R. (2009) Shifting the genomic gold standard for the prokaryotic species definition. Proc. Natl. Acad. Sci. U.S.A. 106, 19126-19131.

[60] Rozen, S., Skaletsky, H.J. (1999) Primer3 on the www for General Users and for Biologist Programmers. Meth. Mol. Biol. 132, 365-386.

[61] Sawana, A., Adeolu, M., Gupta, R.S. (2014) Molecular signatures and phylogenomic analysis of the genus Burkholderia: proposal for division of this genus into the emended genus Burkholderia 
containing pathogenic organisms and a new genus Paraburkholderia gen. nov. harboring environmental species. Front. Genet. 5, 429. doi:10.3389/fgene.2014.00429

[62] Schnitzler, J., Barraclough, T.G., Boatwright, J.S., Goldblatt, P., Manning, J.C., Powell, M.P., Rebelo, T., Savolainen, V. (2011) Causes of plant diversification in the Cape biodiversity hotspot of South Africa. Syst. Biol. 60, 343-357.

[63] Schoen, C., Tettelin, H., Parkhill, J., Frosch, M. (2009) Genome flexibility in Neisseria meningitidis. Vaccine 27, B103-B111.

[64] Sheu, S-Y., Chou, J-H., Bontemps, C., Elliott, G.N., Gross, E., dos Reis Junior, F.B., Melkonian, R., Moulin, L., James, E.K., Sprent, J.I., Young, J.P.W., Chen, W-M. (2013) Burkholderia diazotrophica sp. nov., isolated from root nodules of Mimosa spp. Int. J. Syst. Evol. Microbiol. 63, 435-441.

[65] Sheu, S-Y., Chou, J-H., Bontemps, C., Elliott, G.N., Gross, E., James, E.K., Sprent, J.I., Young, J.P.W., Chen, W-M. (2012) Burkholderia symbiotica sp. nov., isolated from root nodules of Mimosa spp. native to north-east Brazil. Int. J. Syst. Evol. Microbiol. 62, 2272-2278.

[66] Sites, J.W. Jr., Marshall, J.C. (2004) Operational criteria for delimiting species. Annu. Rev. Ecol. Evol. Syst. 35, 199-229.

[67] Stackebrandt, E., Ebers, J. (2006) Taxonomic parameters revisited: tarnished gold standards. Microbiol. Today 33, 152 - 155.

[68] Stackebrandt, E., Goebel, B.M. (1994) Taxonomic note: a place for DNA-DNA reassociation and 16S rRNA sequence analysis in the present species definition in bacteriology. Int. J. Syst. Bacteriol. 44, 846-849.

[69] Steenkamp, E.T., Wright, J., Baldauf, S.L. (2006) The protistan origins of animals and fungi. Mol. Biol. Evol. 23, 93-106. 
[70] Tamura, K., Nei, M. (1993) Estimation of the number of nucleotide substitutions in the control region of mitochondrial DNA in humans and chimpanzees. Mol. Biol. Evol. 10, 512-526.

[71] Tamura, K., Peterson, D., Peterson, N., Stecher, G., Nei, M., Kumar, S. (2011) MEGA5: Molecular Evolutionary Genetics Analysis using Maximum Likelihood, Evolutionary Distance, and Maximum Parsimony Methods. Mol. Biol. Evol. 28, 2731-2739.

[72] Tamura, K., Stecher, G., Peterson, D., Filipski, A., Kumar, S. (2013) MEGA6: Molecular Evolutionary Genetics Analysis Version 6.0. Mol. Biol. Evol. 30, 2725-2729.

[73] Tavaré, S. (1986) Some probabilistic and statistical problems in the analysis of DNA sequences. In: Miura, R.M. (Ed.), Some mathematical questions in biology-DNA sequence analysis. Rhode Island: American Mathematical Society, pp. 57-86.

[74] Vaidya, G., Lohman, D.J., Meier, R. (2011) SequenceMatrix: concatenation software for the fast assembly of multi-gene datasets with character set and codon information. Cladistics 27, 171-180. Accessible at: http://dx.doi.org/10.1111/j.1096-0031.2010.00329.x

[75] Vandamme, P., Dawyndt, P. (2011) Classification and identification of the Burkholderia cepacia complex: past, present and future. Syst. Appl. Microbiol. 34, 87-95.

[76] Vandamme, P., Goris, J., Chen, W-M., de Vos, P., Willems, A. (2002) Burkholderia tuberum sp. nov. and Burkholderia phymatum sp. nov., nodulate the roots of tropical legumes. Syst. Appl. Microbiol. 25, 507-512.

[77] Vandamme, P., Opelt, K., Knöchel, N., Berg, C., Schönmann, S., De Brandt, E., Eberl, L., Falsen, E., Berg, G. (2007) Burkholderia bryophila sp. nov. and Burkholderia megapolitana sp. nov., moss-associated species with antifungal and plant-growth-promoting properties. Int. J. Syst. Evol. Microbiol. 57, 2228-2235. 
[78] Vandamme, P., Peeters, C. (2014) Time to revisit polyphasic taxonomy. Antonie van Leeuwenhoek 106, 57-65. doi:10.1007/s10482-014-0148-x

[79] Vermis, K., Coenye, T., LiPuma, J.J., Mahenthiralingam, E., Nelis, H.J., Vandamme, P. (2004) Proposal to accommodate Burkholderia cepacia genomovar VI as Burkholderia dolosa sp. nov. Int. J. Syst. Evol. Microbiol. 54, 689-691.

[80] Willems, A. (2006) The taxonomy of rhizobia: an overview. Plant and Soil 287, 3-14

[81] Whitman, W.B., Woyke, T., Klenk, H-P., Zhou, Y., Lilburn, T.G., Beck, B.J., De Vos, P., Vandamme P., Eisen, J.A., Garrity, G., Hugenholtz, P., Kyrpides, N.C. (2015) Genomic Encyclopedia of Bacterial and Archaeal Type Strains, Phase III: the genomes of soil and plant-associated and newly described type strains. Standards in Genomic Sciences 10.26, 1-6. doi:10.1186/s40793-015-0017-x

[82] Yamaguchi, Y., Park, J-H., Inouye, M. (2011) Toxin-antitoxin systems in Bacteria and Archaea. Annu. Rev. Genet. 45, 61-79. 